Article

\title{
The Venom of the Spider Selenocosmia Jiafu Contains Various Neurotoxins Acting on Voltage-Gated Ion Channels in Rat Dorsal Root Ganglion Neurons
}

\author{
Zhaotun Hu ${ }^{1,2}$, Xi Zhou ${ }^{1}$, Jia Chen ${ }^{1}$, Cheng Tang ${ }^{1}$, Zhen Xiao ${ }^{2}$, Dazhong Ying ${ }^{1}$, \\ Zhonghua Liu ${ }^{1, *}$ and Songping Liang ${ }^{1, *}$
}

1 Key Laboratory of Protein Chemistry and Developmental Biology of the Ministry of Education, College of Life Sciences, Hunan Normal University, Changsha, Hunan 410081, China;

E-Mails: huzhaotun@163.com (Z.H.); zhouxi016@163.com (X.Z.); chenjia113322@163.com (J.C.); tangcheng1985ss@sina.com (C.T.); dazhongyin002@126.com (D.Y.)

2 Key Laboratory of Research and Utilization of Ethnomedicinal Plant Resources of Hunan Province, Department of Life Science, Huaihua College, Huaihua, Hunan 418008, China;

E-Mail: 405542716@qq.com

* Authors to whom correspondence should be addressed; E-Mails: liuzh@hunnu.edu.cn (Z.L.); liangsp@hunnu.edu.cn (S.L.); Tel.: +86-731-8887-2556 (Z.L.\& S.L.);

Fax: +86-731-8886-1304 (Z.L. \& S.L.).

Received: 27 January 2014; in revised form: 10 February 2014 / Accepted: 17 February 2014 / Published: 5 March 2014

\begin{abstract}
Selenocosmia jiafu is a medium-sized theraphosid spider and an attractive source of venom, because it can be bred in captivity and it produces large amounts of venom. We performed reversed-phase high-performance liquid chromatography (RP-HPLC) and matrix-assisted laser-desorption/ionization time-of-flight mass spectrometry (MALDI-TOF-MS) analyses and showed that $S$. jiafu venom contains hundreds of peptides with a predominant mass of 3000-4500 Da. Patch clamp analyses indicated that the venom could inhibit voltage-gated $\mathrm{Na}^{+}, \mathrm{K}^{+}$and $\mathrm{Ca}^{2+}$ channels in rat dorsal root ganglion (DRG) neurons. The venom exhibited inhibitory effects on tetrodotoxin-resistant (TTX-R) $\mathrm{Na}^{+}$currents and T-type $\mathrm{Ca}^{2+}$ currents, suggesting the presence of antagonists to both channel types and providing a valuable tool for the investigation of these channels and for drug development. Intra-abdominal injection of the venom had severe toxic effects on cockroaches and caused death at higher concentrations. The $\mathrm{LD}_{50}$ was $84.24 \mu \mathrm{g} / \mathrm{g}$ of body weight in the cockroach. However, no visible symptoms or behavioral changes were
\end{abstract}


detected after intraperitoneal injection of the venom into mice even at doses up to $10 \mathrm{mg} / \mathrm{kg}$ body weight. Our results provide a basis for further case-by-case investigations of peptide toxins from this venom.

Keywords: Selenocosmia jiafu; spider venom; RP-HPLC; MALDI-TOF-MS; patch clamp analysis; voltage-gated ion channel; DRG neuron

\section{Introduction}

Spiders evolved approximately 400 million years ago from an arachnid ancestor [1]. Excluding insects, which are the primary prey of spiders, spiders are the most diverse and successful terrestrial invertebrates [2]. There are 43,244 described species in approximately 111 families, with an even greater number awaiting characterization [3]. Spiders are distributed all over the world and have conquered all ecological environments. Most spiders are relatively small (2-10 $\mathrm{mm}$ body length), although some large tarantulas may reach a body length of $80-90 \mathrm{~mm}$. Many are specialized as snare builders (web spiders), whereas others actively hunt their prey (ground spiders or wandering spiders).

All spiders are predators and, with the exception of Uloboridae and Holarcheae, all spiders have a venom apparatus. The venom apparatus of spiders consists of a pair of chelicerae and venom glands. The shape and position of the venom gland differs among species. In the large "theraphosids", the venom glands are quite small and lie inside the chelicerae. In the genus Atypus, the glands are composite, while in Filistata they are of a multilobular type, and in Scytodes they are bilobular [4].

$S$. jiafu is one of the venomous spider species found in the hilly areas of Yunnan province and Guangxi province in the south of China. As a new species, S. jiafu was first discovered in Yunnan Province in 2008 [5]. The authors of this study found this spider specimen in 2012 in a hilly area of Ninming county in the Guangxi province. $S$. jiafu is a medium-bodied hairy spider (Figure 1A). The male and female $S$. jiafu spiders are described as follows: The male carapace is yellow-brown with a reticulated patch and dense fluff, and long hairs at its margins; yellow-brown chelicerae are covered with long brown hairs dorsally and yellow-brown legs are densely covered with long and short hairs; a pale gray oval abdomen is sparsely covered with long brown hairs and densely covered with short light-brown hairs; no distinct patterns are observed on the abdomen. The female carapace and chelicerae are similar to those of the male; the legs are thicker and shorter than those of the male and some regions of the legs show no hair longitudinally; the abdomen is oval with thin light yellow hairs and without any distinct patterns. The spider has a body length of 3-6 $\mathrm{cm}$ or $6-10 \mathrm{~cm}$ with the legs extended (Figure 1B). The average weight of a mature spider is $4.11 \pm 0.85 \mathrm{~g}$ (female) or $3.28 \pm 0.67 \mathrm{~g}$ (male). It lives underground on open areas of hillsides or at the fringe of cultivated lands, but rarely in regions of dense forest or heavy undergrowth. The burrow in which the spider lives is constructed horizontally or with a slight slant and is usually $6-13 \mathrm{~cm}$ wide and $60-70 \mathrm{~cm}$ long. The entrance of the burrow is often covered with white spider silk, and the entire burrow appears as a loose webbing tube covered with silk around the inner wall (Figure 1C,D).

Spider venoms are known to contain several classes of peptide toxins that target voltage-gated ion channels and have been considered as a potential source of new compounds with specific 
pharmacological properties $[2,6,7]$. The potential of venom components as pharmacological tools and as potential leads for the development of new drugs and pesticides has recently been recognized. As a result, venoms and toxins have generated broad interest in the scientific community and in the agrochemical and pharmaceutical industries in recent years. Moreover, different spider species contain distinct toxin molecules. The venom of the spider $S$. jiafu could be a novel source for the identification of novel peptide toxins acting on voltage-gated ion channels. Therefore, in the present study, we conducted a biochemical and electrophysiological investigation of the venom of $S$. jiafu. We showed that the venom contains diverse peptides and possesses inhibitory activities on voltage-gated $\mathrm{Na}^{+}, \mathrm{K}^{+}$and $\mathrm{Ca}^{2+}$ channels in rat dorsal root ganglion (DRG) neurons. These results provide clues for the purification and characterization of specific toxins in future studies.

Figure 1. The spider $S$. jiafu and habitat burrow of the spider $S$. jiafu: (A) the spider S. jiafu; (B) A female $S$. jiafu has a body length of $50 \mathrm{~mm}$ and a leg span of $90 \mathrm{~mm}$; (C) the burrow usually has a loose silken tube at the entrance; and (D) the construction of the burrow is horizontal or at a slight angle and the inner wall is covered with silk.
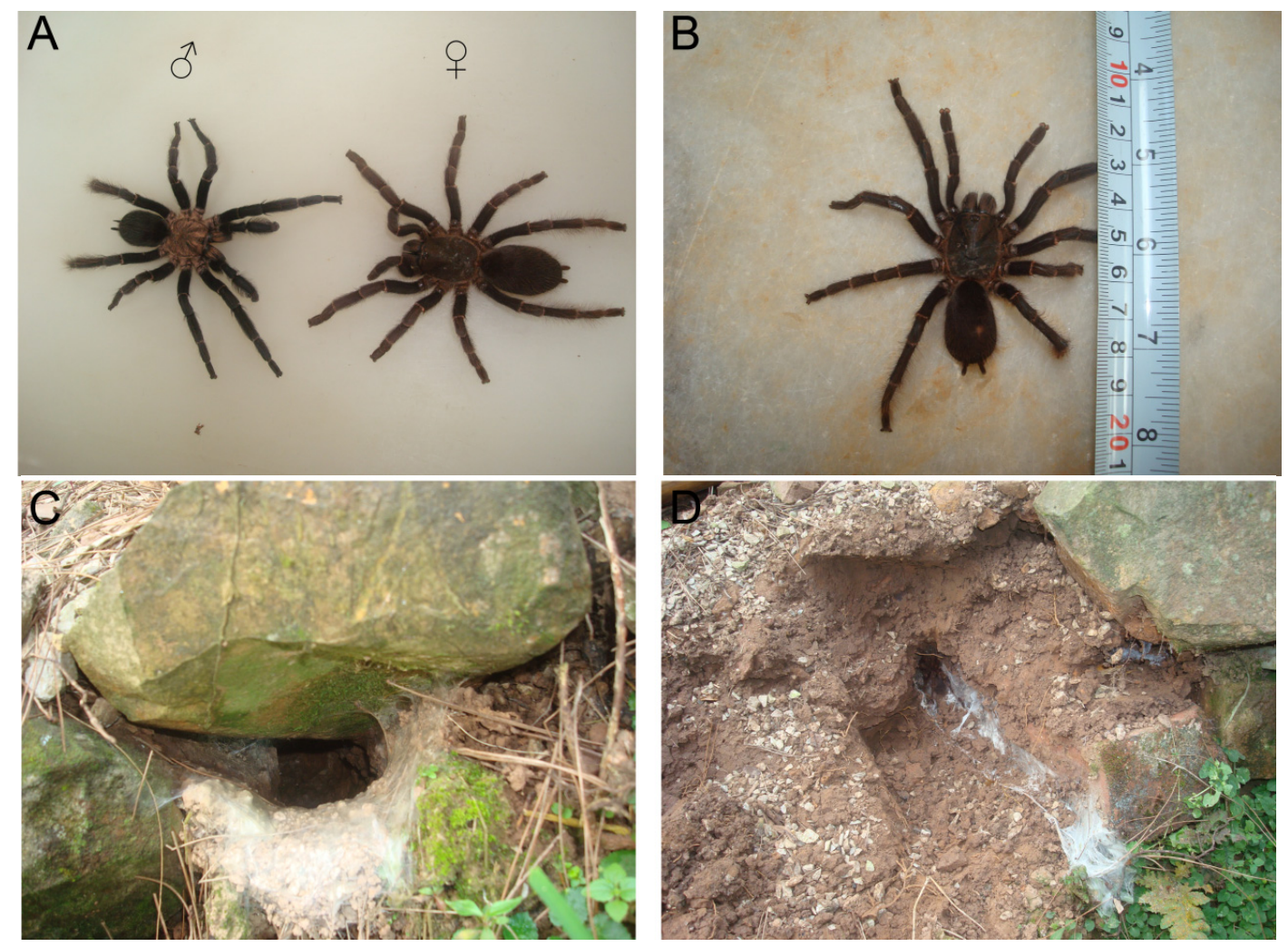

\section{Results and Discussion}

\subsection{Reversed-Phase High-Performance Liquid Chromatography (RP-HPLC), Matrix-Assisted Laser-Desorption/Ionization Time-of-Flight Mass Spectrometry (MALDI-TOF-MS) and Sodium Dodecyl Sulfate-Polyacrylamide Gel Electrophoresis (SDS-PAGE) Analyses of the Venom}

The spider $S$. jiafu can expel venom from the chelicerae after electrical stimulation. The venom is a clear and colorless liquid, easily soluble in water. Each $S$. jiafu spider yields approximately 5-20 $\mu \mathrm{L}$ venom. A typical RP-HPLC chromatogram of the venom of the spider $S$. jiafu is shown in Figure 2A. 
More than 40 fractions were eluted and monitored at $215 \mathrm{~nm}$. Most of the fractions were eluted with retention times of 5-15 min and $25-40 \mathrm{~min}$, corresponding to $5 \%-15 \%$ and $25 \%-40 \%$ acetonitrile, respectively. The fractions eluted at 5-15 min did not display any mass peaks in MALDI-TOF-MS spectra, indicating that they may contain low molecular mass organic compounds and salts. Spider venoms are commonly composed of proteins, peptides, low molecular mass organic compounds and salts, and peptides are the most abundant components of most spider venoms [8]. Therefore, we determined the mass distribution of the venom peptides by MALDI-TOF MS. As shown in Figure 2B, approximately 20 peaks were detected in a mass range from $1000 \mathrm{Da}$ to $10,000 \mathrm{Da}$. Most of these peaks were localized in the range of 3000-4500 Da.

To explore the molecular weight distribution of the venom proteins, the venom was analyzed by SDS-PAGE using standard protocols. Except for polypeptides with molecular weights below $10 \mathrm{kD}$, the venomous proteins were mainly distributed in three bands on SDS-PAGE corresponding to the molecular weights of approximately $50 \mathrm{kD}, 72 \mathrm{kD}$ and $90 \mathrm{kD}$ (Figure 2C).

Figure 2. The complexity of the venom peptides: (A) reversed-phase high-performance liquid chromatography (RP-HPLC) separation of $1 \mathrm{mg}$ of soluble venom from $S$. jiafu in an analytical C18 column equilibrated with solution A (distilled water in $0.1 \%$ TFA), using a gradient from $0 \%$ to $50 \%$ of solution B (acetonitrile in $0.1 \%$ TFA) over 50 min with a flow rate of $1 \mathrm{~mL} / \mathrm{min}$. Absorbance was read at $215 \mathrm{~nm}$. (B) Matrix-assisted laser-desorption/ionization time-of-flight mass spectrometry (MALDI-TOF-MS) of S. jiafu venom. (C) Sodium dodecyl sulfate-polyacrylamide gel electrophoresis (SDS-PAGE) of the venom of the spider S. jiafu. 1: Marker; 2 and 3: Venom.
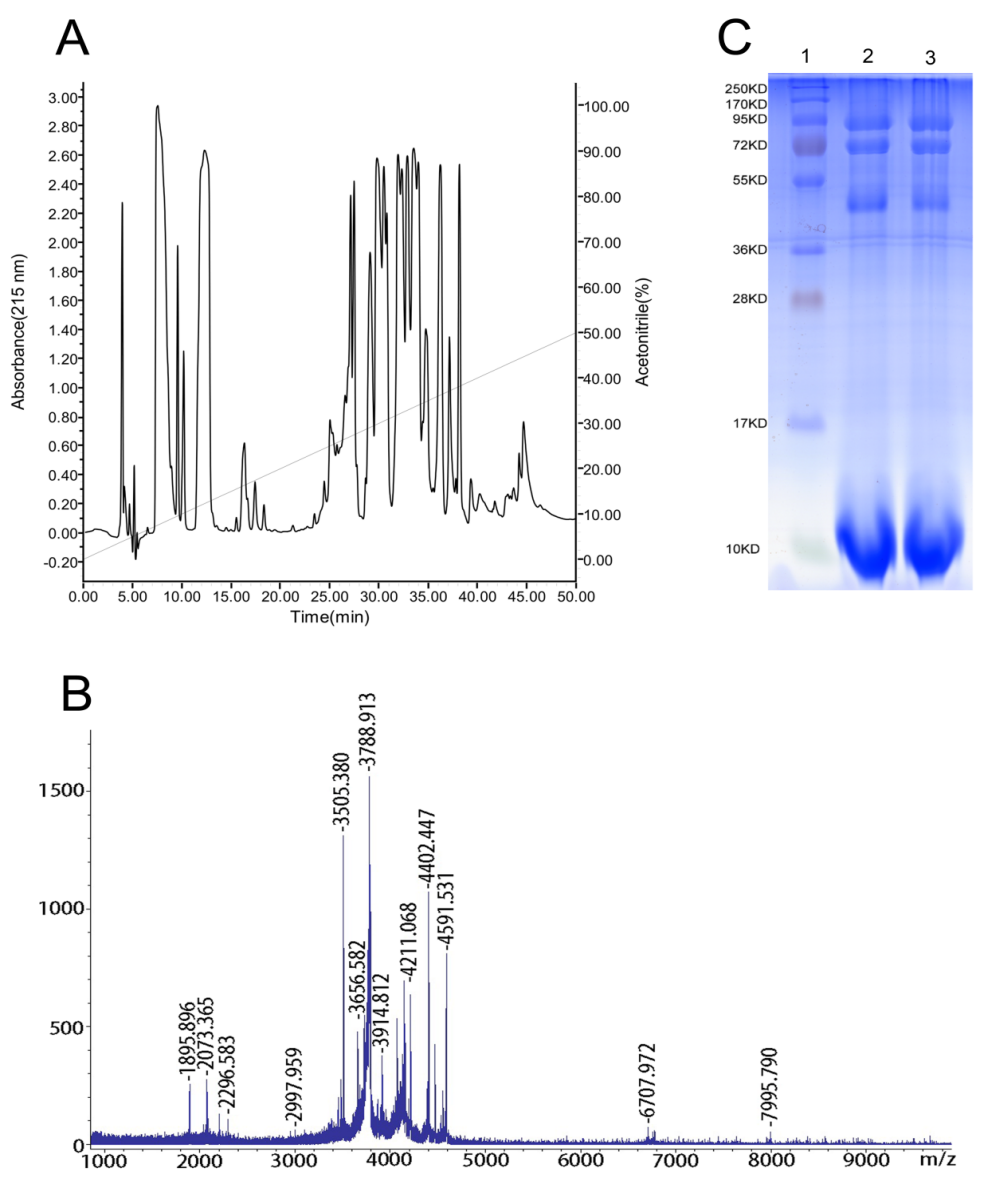
To examine the diversity of $S$. jiafu venomous peptides, MALDI-TOF-MS coupled offline to chromatographic separation was used to analyze the venom of the spider $S$. jiafu. This strategy was developed by Escoubas et al. [9] who plotted 3D landscapes to conceptualize the complexity of Australian funnel-web spider venoms. Their studies demonstrated that the venoms from these spiders contain many hundreds of peptides that follow a bimodal distribution, with the majority of peptides in the 3000-5000 Da mass range and a second less pronounced group in the 6500-8500 Da range. Similar results were reported in our previous studies of venoms from the Chinese tarantula spiders Ornithoctonus huwena [10], Ornithoctonus hainana [11] and Chilobrachys jingzhao [12]. We focused exclusively on the peptide fractions in the mass range from $1000 \mathrm{Da}$ to $10,000 \mathrm{Da}$. As shown in Figure 3A, peptides of several masses were detected in almost all fractions analyzed, and some fractions even contained more than 10 peptides with different masses, suggesting that multiple peptides were co-eluted in each fraction. More than 200 peptides of different masses were identified, highlighting the complexity of the peptides in the venom (Figure 3B).

All the experimental data were integrated to construct a 3D venom landscape in which the mass spectral intensities were plotted as a function of both $\mathrm{m} / \mathrm{z}$ and the RP-HPLC elution time (Figure 3C), thus providing a detailed overview of $S$. jiafu venomous peptides. Different peptides that were not completely separated by RP-HPLC can be distinguished by their relative mass values in the 3D plot.

Figure 3. (A) Distribution of peptide molecular masses as a function of RP-HPLC elution time as determined by MALDI-TOF-MS analysis of individual RP-HPLC fractions of the venom from $S$. jiafu. (B) Histograms show the abundance of peptide toxins in the venom, sorted into 500 Da molecular mass classes. The overlaid curve shows the cumulative total of peptide masses identified from LC-MALDI analyses. (C) 3D venom landscape of S. jiafu. MALDI-TOF-MS peak intensities ( $z$-axis, counts) were plotted as a function of hydrophobicity ( $x$-axis, RP-HPLC fraction number) and mass $(y$-axis, $m / z)$ to produce a $3 \mathrm{D}$ contour plot.
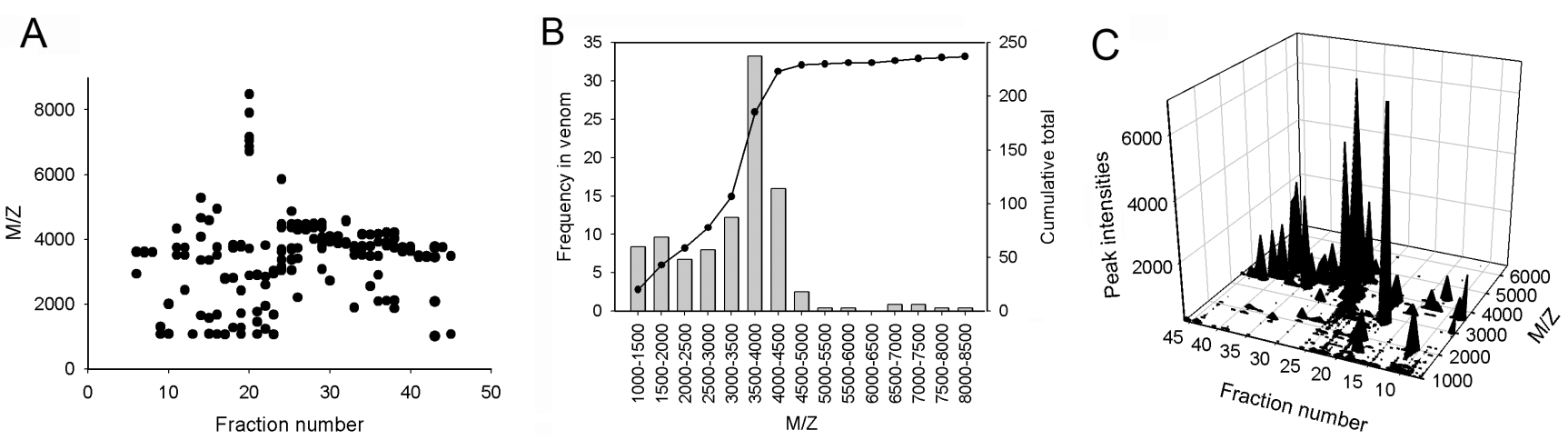

\subsection{Effects of the Venom on Voltage-Gated Sodium Channels (VGSCs)}

VGSCs $\left(\mathrm{Na}_{\mathrm{v}}\right)$ are essential for the rapid depolarization of nerve and muscle. $\mathrm{Na}_{\mathrm{v}}$ channels initiate and propagate action potentials in excitable cells. Because they underlie several clinical disorders such as epileptic seizures and cardiac arrhythmias, they are important drug targets [13]. Two types of $\mathrm{Na}^{+}$currents $\left(\mathrm{I}_{\mathrm{Na}}\right)$ have been identified on the basis of their sensitivity to tetrodotoxin (TTX), one is 
insensitive to TTX (up to $0.1 \mathrm{mM}$ ) while the other type is blocked by approximately $1 \mathrm{nM}$ TTX [14]. Both types of $\mathrm{Na}_{\mathrm{v}}$ channels are present in rat DRG neurons.

The effects of the $S$. jiafu venom on $\mathrm{Na}_{\mathrm{v}}$ channels in rat DRG neurons were therefore examined using the whole-cell patch-clamp technique. DRG neurons with a large diameter $(>35 \mu \mathrm{m})$ and those with a relatively small diameter $(<20 \mu \mathrm{m})$ were selected for measuring tetrodotoxin-sensitive (TTX-S) and tetrodotoxin-resistant (TTX-R) $\mathrm{Na}^{+}$currents, respectively [15]. The venom had inhibitory activity against $\mathrm{Na}_{\mathrm{v}}$ channels in rat DRG neurons. As shown in Figure 4, $100 \mu \mathrm{g} / \mathrm{mL}$ venom could not only suppress $64.0 \% \pm 6.2 \%(n=5)$ of TTX-S currents but also delay channel inactivation (Figure 4A).

Figure 4. Effects of $S$. jiafu venom on whole-cell $\mathrm{Na}_{\mathrm{v}}$ channel currents in rat dorsal root ganglion (DRG) neurons. (A) Tetrodotoxin-sensitive (TTX-S) $\mathrm{Na}^{+}$currents were induced by a $50-\mathrm{ms}$ depolarized potential of $-10 \mathrm{mV}$ from a holding potential of $-80 \mathrm{mV}$ in large DRG neurons. TTX-S current amplitude was blocked to $64.0 \% \pm 6.2 \%(n=5)$ by $100 \mu \mathrm{g} / \mathrm{mL}$ venom. (B) Current-voltage (I-V) curves of TTX-S. For current-voltage curves, the currents were elicited by a series of 50-ms depolarizations from a holding potential of $-80 \mathrm{mV}$, with a test potential ranging from $-80 \mathrm{mV}$ to $+90 \mathrm{mV}$ at increments of $+10 \mathrm{mV}$. (C) $\mathrm{Na}^{+}$ currents were evoked by a 50-ms depolarized potential of $-10 \mathrm{mV}$ from a holding potential of $-80 \mathrm{mV}$ in medium size DRG neurons. At $200 \mathrm{nM}$ tetrodotoxin (TTX), the remnant tetrodotoxin-resistant (TTX-R) currents were inhibited by $46.5 \% \pm 3.8 \%(n=5)$ in the presence of $100 \mu \mathrm{g} / \mathrm{mL}$ venom. (D) Current-voltage (I-V) curves of TTX-R. For current-voltage curves, the currents were elicited by a series of 50-ms depolarizations from a holding potential of $-80 \mathrm{mV}$, with a test potential ranging from $-80 \mathrm{mV}$ to $+50 \mathrm{mV}$ at increments of $+10 \mathrm{mV}$. The data were expressed as mean $\pm \mathrm{SE}(n=5)$.

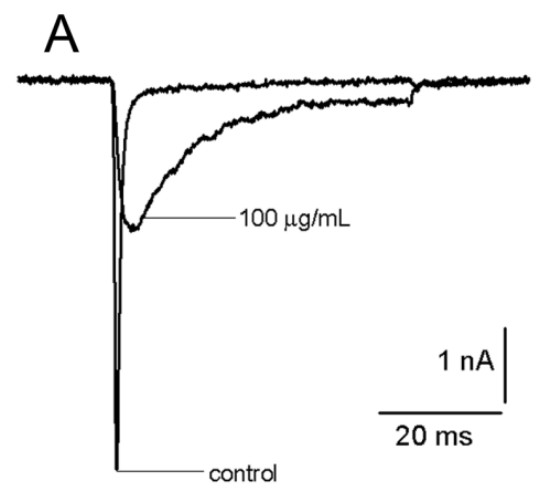

B

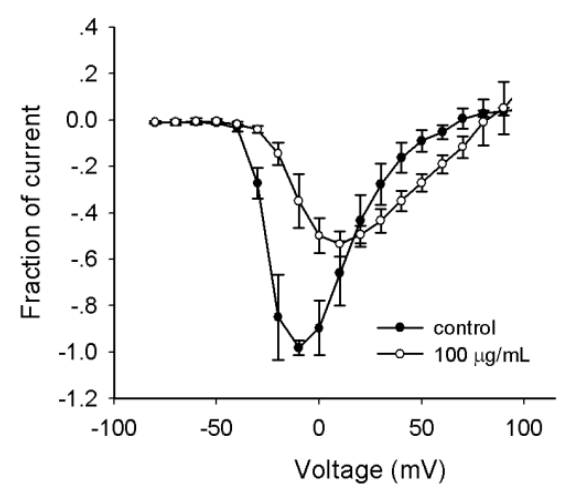

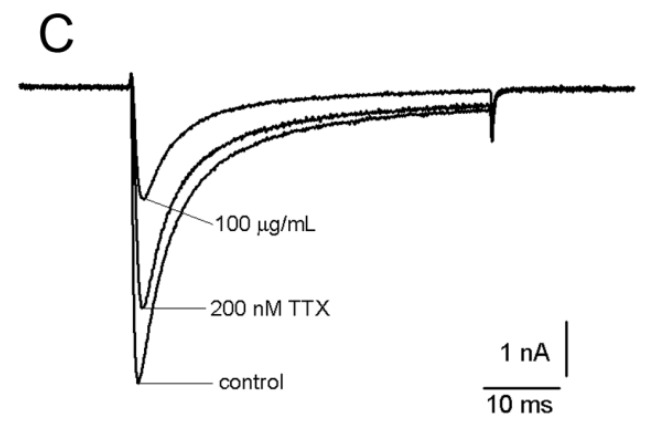

$\mathrm{D}$

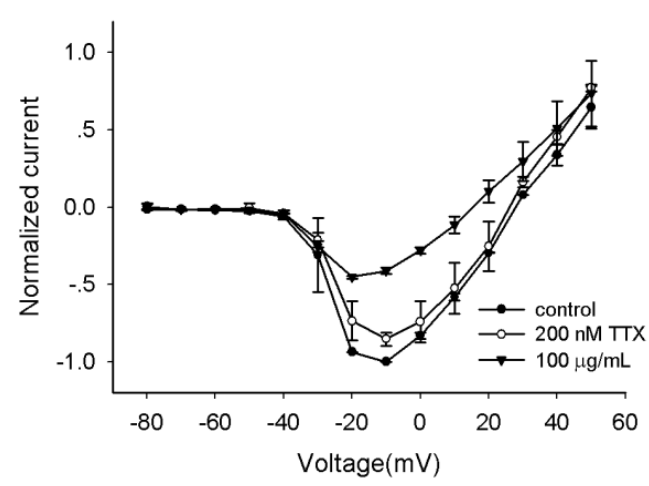


The time constants for inactivation before and after the treatment of the venom were $0.7 \pm 0.2 \mathrm{~ms}$ and $7.5 \pm 1.4 \mathrm{~ms}(n=5)$, respectively. In the presence of the venom, the remnant currents could be completely blocked by $200 \mathrm{nM}$ TTX, indicating the TTX-S property of the VGSC $\left(\mathrm{Na}_{\mathrm{v}}\right)$ currents expressed in large diameter neurons. The current-voltage (I-V) curves showed that the venom changed the activation of TTX-S currents by a depolarizing shift of the activation voltage of the peak current from $-10 \mathrm{mV}$ to $+10 \mathrm{mV}(n=5)$ (Figure 4B). The half-activation voltage in the presence of the venom was $-8.9 \pm 0.2 \mathrm{mV}$, compared to $-24.6 \pm 0.1 \mathrm{mV}(n=5)$ in the control. To test the inhibitory effect of the venom on TTX-R currents, $200 \mathrm{nM}$ TTX was used to separate the TTX-R currents from the TTX-S currents. As shown in Figure $4 \mathrm{C}$, the amplitude of the remnant TTX-R currents was reduced by $46.5 \% \pm 3.8 \%(n=5)$ in the presence of $100 \mu \mathrm{g} / \mathrm{mL}$ venom, suggesting that antagonists of TTX-R $\mathrm{Na}_{\mathrm{v}}$ channels are present in the venom. The current-voltage (I-V) curves showed that the venom changed the activation of TTX-R currents by a depolarizing shift of the activation voltage of the peak current from $-10 \mathrm{mV}$ to $-20 \mathrm{mV}(n=5)$ (Figure 4D). The half-activation voltages before and after the venom treatment were $-22.7 \pm 0.5 \mathrm{mV}$ to $-27.2 \pm 0.2 \mathrm{mV}(n=5)$, respectively. Rat DRG neurons express two isoforms of TTX-R $\mathrm{Na}_{\mathrm{v}}$ channels, $\mathrm{Na}_{\mathrm{v}} 1.8$ and $\mathrm{Na}_{\mathrm{v}} 1.9 . \mathrm{Na}_{\mathrm{v}} 1.8$ is involved in neuropathic pain [16], whereas $\mathrm{Na}_{\mathrm{v}} 1.9$ is implicated in inflammatory pain modulation through the upregulation of neuronal excitability in DRG neurons [17]. Our data indicate that $\mathrm{Na}_{\mathrm{v}} 1.8$ and/or $\mathrm{Na}_{\mathrm{v}} 1.9$ antagonists can be identified in the venom of $S$. jiafu.

\subsection{Effects of the Venom on Voltage-Gated Potassium Channels}

DRG neurons express many types of $\mathrm{K}^{+}$channels including voltage-gated $\left(\mathrm{K}_{\mathrm{V}}\right)$, inwardly rectifying $\left(\mathrm{K}_{\mathrm{ir}}\right), \mathrm{Ca}^{2+}$ activated $\left(\mathrm{K}_{\mathrm{Ca}}\right)$ and background (leak, $\left.\mathrm{K}_{2 \mathrm{P}}\right) \mathrm{K}^{+}$channels. These channels contribute to the regulation of membrane repolarization, resting membrane potential, frequency of firing, and excitability of sensory neurons $[18,19]$. Among various $\mathrm{K}^{+}$channels, $\mathrm{K}_{\mathrm{v}}$ channels play a crucial role in returning the depolarized cell to the resting state, and the inhibition of these channels leads to the broadening of action potentials [20]. Our study showed that $100 \mu \mathrm{g} / \mathrm{mL}$ venom inhibited $\mathrm{K}^{+}$currents by approximately $44.2 \% \pm 5.3 \%(n=5)$ (Figure 5A). Figure 5B shows the current-voltage curves obtained before and after venom treatment, indicating that the venom altered the initial activation voltage of $\mathrm{K}^{+}$currents in rat DRG neurons. At a concentration of $100 \mu \mathrm{g} / \mathrm{mL}$, it shifted the initial activation voltage from $-50 \pm 2.6 \mathrm{mV}$ to $-20 \pm 1.7 \mathrm{mV}$. The half-activation voltages before and after the application of the venom were $21.9 \pm 2.8 \mathrm{mV}$ and $25.5 \pm 2.0 \mathrm{mV}$, respectively. 
Figure 5. Effects of $S$. jiafu venom on whole-cell $\mathrm{K}_{\mathrm{v}}$ channel currents in rat DRG neurons. (A) $\mathrm{K}_{\mathrm{V}}$ currents were evoked by a 500-ms depolarized potential of $10 \mathrm{mV}$ from a holding potential of $-80 \mathrm{mV}$. Application of $100 \mu \mathrm{g} / \mathrm{mL}$ of venom led to a reduction of $\mathrm{K}^{+}$currents of $44.2 \% \pm 5.3 \%(n=5)$; (B) Normalized current-voltage relation of $\mathrm{K}^{+}$currents before (filled circles) and after (open circles) venom treatment. Currents were elicited by a series of 500-ms depolarizations from a holding potential of $-80 \mathrm{mV}$ to $+60 \mathrm{mV}$ in $10-\mathrm{mV}$ steps. The data were expressed as mean $\pm \operatorname{S.E}(n=5)$.

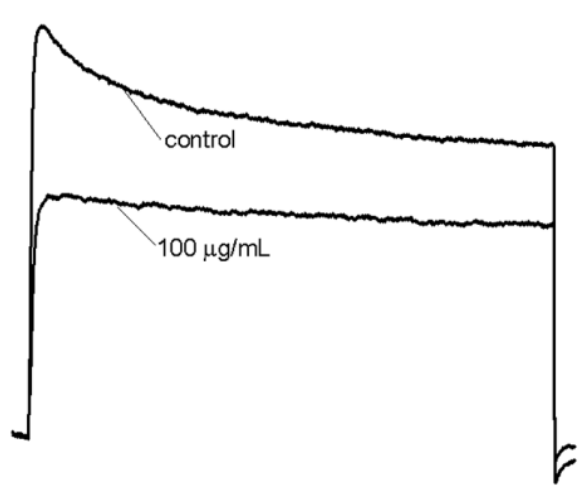

(A)

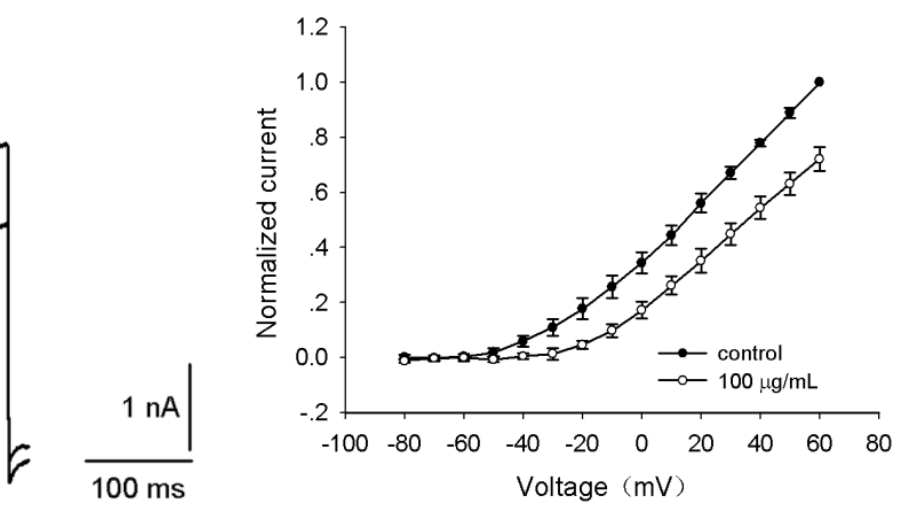

(B)

\subsection{Effects of the Venom on Voltage-Gated Calcium Channels}

$\mathrm{Ca}^{2+}$ entry into cells through voltage-gated $\mathrm{Ca}^{2+}$ channels mediates many physiological processes including neurotransmitter release, neurosecretion, neuronal excitation, survival of neurons, and regulation of gene expression. Currently, five main types of $\mathrm{Ca}^{2+}$ channels ( $T, \mathrm{~L}, \mathrm{~N}, \mathrm{P} / \mathrm{Q}$, and $\mathrm{R}$ ) have been identified in vertebrate cells based on their physiological and pharmacological properties [21-23]. High-voltage-activated (HVA) L-, N-, P/Q- and R-type $\mathrm{Ca}^{2+}$ channels require strong depolarization for activation and are essentially implicated in neurotransmitter release. Low voltage-activated (LVA) T-type currents can be activated by small depolarizations, are rapidly inactivated, and modulate pacemaker type repetitive activity in cardiac cells and neurons [24]. As shown in Figure 6A, the addition of $100 \mu \mathrm{g} / \mathrm{mL}$ venom could inhibit approximately $65.4 \% \pm 9.5 \%(n=5)$ of total $\mathrm{Ca}_{\mathrm{v}}$ currents in rat DRG neurons, which were activated by a $150-\mathrm{ms}$ step depolarization to $+10 \mathrm{mV}$ from a holding potential of $-90 \mathrm{mV}$. Figure $6 \mathrm{~B}$ shows the $\mathrm{I}-\mathrm{V}$ curves of total $\mathrm{Ca}^{2+}$ currents, indicating that the venom caused no change on the initial activated voltage, the active voltage of peak inward current and the reversal potential of $\mathrm{Ca}^{2+}$ currents.

Next, we investigated whether the venom had inhibitory activity against both types of $\mathrm{Ca}_{\mathrm{v}}$ channels in rat DRG neurons. As shown in Figure 6C, the application of $100 \mu \mathrm{g} / \mathrm{mL}$ venom led to an approximately $77.7 \% \pm 9.9 \%(n=5)$ reduction of LVA currents elicited by a 150 -ms step depolarization to $-40 \mathrm{mV}$ from a holding potential of $-90 \mathrm{mV}$. T-type channels are widely distributed in pain pathway neurons and implicated in pain modulation. Since no peptide antagonist of T-type channels has been identified to date, the identification of inhibitors of T-type channels from the venom of $S$. jiafu is important. Meanwhile, treatment with $50 \mu \mathrm{g} / \mathrm{mL}$ venom resulted in a $74.9 \% \pm 2.8 \%(n=5)$ reduction of HVA currents activated by a $150 \mathrm{~ms}$ step depolarization to $+10 \mathrm{mV}$ from a holding potential of $-40 \mathrm{mV}$ (Figure 6D). Several types of HVA Ca $\mathrm{V}_{\mathrm{v}}$ channels are present in rat DRG neurons. N-type 
channel blockers profoundly attenuate hyperalgesia and allodynia in response to mechanical, chemical or thermal stimulation [25]. P/Q-type channels have been linked genetically to specific diseases including epilepsy, ataxia and migraines [26]. We expect that inhibitors of a specific $\mathrm{HVA} \mathrm{Ca} \mathrm{V}_{\mathrm{v}}$ channel would be identified from the venom of $S$. jiafu.

Figure 6. Effects of $S$. jiafu venom on whole-cell $\mathrm{Ca}_{\mathrm{v}}$ channel currents in rat DRG neurons. (A) The application of $100 \mu \mathrm{g} / \mathrm{mL}$ of venom inhibited $65.4 \% \pm 9.5 \%(n=5)$ of total $\mathrm{Ca}_{\mathrm{v}}$ currents evoked by a $150-\mathrm{ms}$ depolarization to $10 \mathrm{mV}$ from a holding potential of $-90 \mathrm{mV}$. (B) Normalized current-voltage relationships of $\mathrm{Ca}_{\mathrm{v}}$ currents in the presence and absence of $100 \mu \mathrm{g} / \mathrm{mL}$ of venom. Currents were elicited by a series of $150-\mathrm{ms}$ depolarizations from $-80 \mathrm{mV}$ to $+90 \mathrm{mV}$ in $5-\mathrm{mV}$ steps with a holding potential of $-90 \mathrm{mV}$. The data were expressed as mean $\pm \mathrm{SE}(n=5)$. (C) The application of $100 \mu \mathrm{g} / \mathrm{mL}$ of venom inhibited $77.7 \% \pm 9.9 \%(n=5)$ of $\mathrm{LVA}-\mathrm{Ca}_{\mathrm{v}}$ currents evoked by a $150-\mathrm{ms}$ depolarization to $-20 \mathrm{mV}$ from a holding potential of $-90 \mathrm{mV}$. (D) The application of $50 \mu \mathrm{g} / \mathrm{mL}$ of venom inhibited $74.9 \% \pm 2.8 \%(n=5)$ of $\mathrm{HVA}-\mathrm{Ca}_{\mathrm{v}}$ currents elicited by a $150-\mathrm{ms}$ depolarization to $+10 \mathrm{mV}$ from a holding potential of $-40 \mathrm{mV}$.

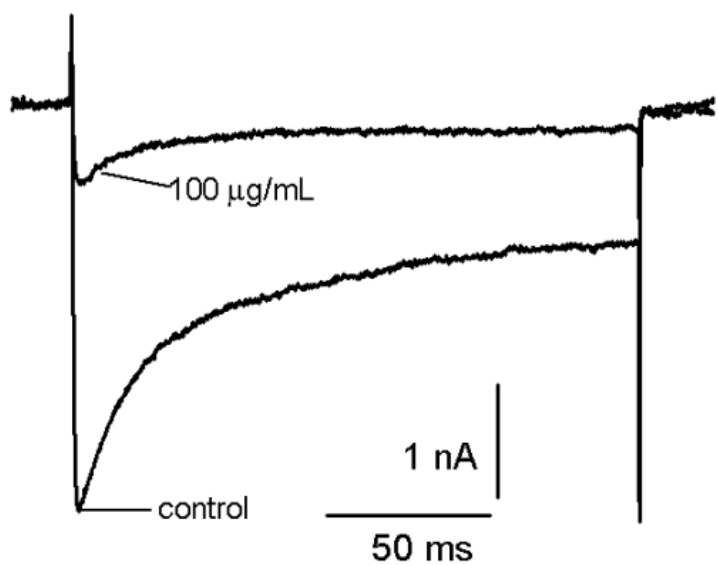

(A)

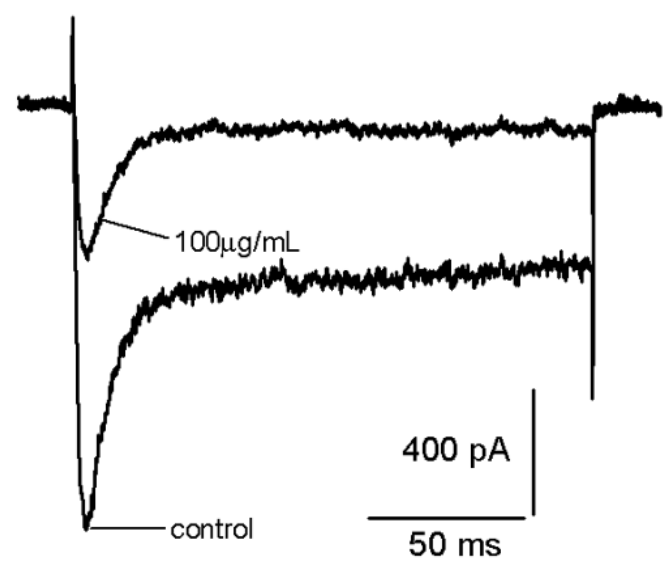

(C)

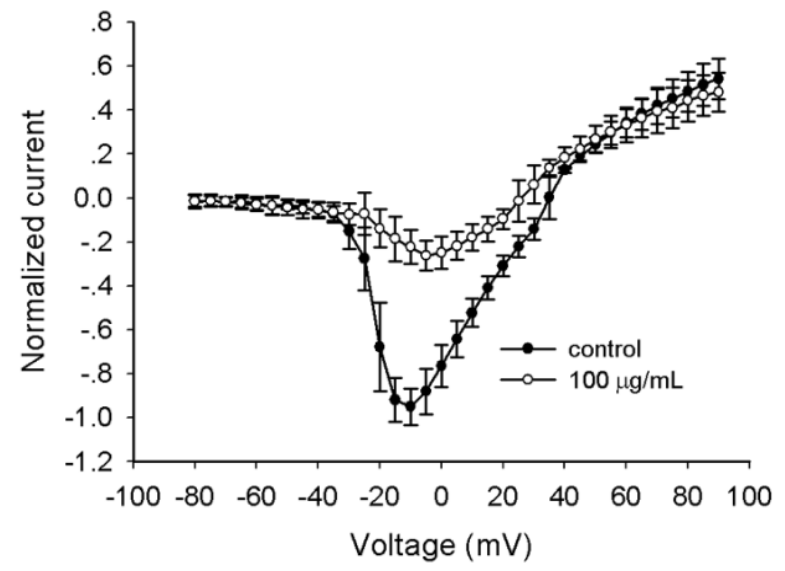

(B)

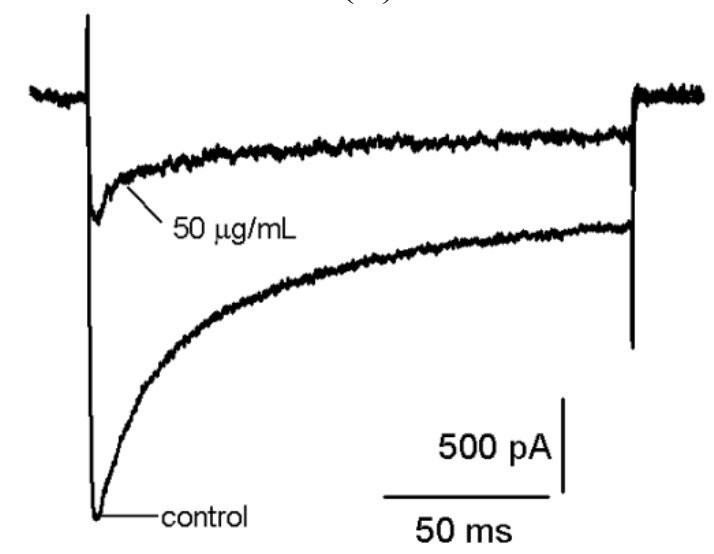

(D)

\subsection{Bioactivity Assays}

We first examined the toxic effects of the venom against mice. It was found that no visible symptom or behavioral change was detected after intraperitoneal injection of the venom into mice even 
at doses less than $10 \mathrm{mg} / \mathrm{kg}$ body weight; at a dose of $20 \mathrm{mg} / \mathrm{kg}$ body weight, mice showed mild symptoms of poisoning including a reduction of the level of activity, rapid breathing, and abdominal trembling. These symptoms subsided within $30 \mathrm{~min}$; at a dose of $46.30 \mathrm{mg} / \mathrm{kg}$ body weight, mice exhibited obvious symptoms of poisoning and finally died 24 min after venom injection. We next checked toxic effects of the venom on the American cockroach (Periplaneta Americana). A large dose injection produced symptoms of poisoning including hind limb paralysis, stumbling during crawling, foot shaking and even death. The $\mathrm{LD}_{50}$ of $S$. jiafu venom in the cockroach was $84.24 \mu \mathrm{g} / \mathrm{g}$ body weight, which is approximately $25 \%$ of the $\mathrm{LD}_{50}$ of $S$. huwena venom in the cockroach (the $\mathrm{LD}_{50}$ of $S$. huwena crude extract against cockroaches is $300 \mu \mathrm{g} / \mathrm{g}$ body weight) [27]. Our data indicate that the venom might contain some factors that target the ion channels of insects and could therefore be valuable for the development of novel insecticides. Further studies will be needed to identify and characterize the components acting on insect ion channels.

\section{Experimental Section}

\subsection{Venom Collection}

The spiders were collected from the hilly area of Ninming county of Guangxi Province in the south of China. Adult female $S$. jiafu spiders were maintained in wooden boxes or plastic pails covered with plastic netting and given water daily. The spiders were fed pig liver (cut into pieces of $1-2 \mathrm{~cm}^{3}$ ), cockroaches or worms every seven days. Stimulation of female $S$. jiafu every two weeks as described in our previous work [28]. The venom was collected by using an electro-pulse stimulator. The two output electrodes of the stimulator were placed in contact with the sides of the root of the spider's chelicerae. Physiological saline was used to enhance electrical conduction. Electrostimulation at 10-15 V and $25-80 \mathrm{~Hz}$ with a pulse time of $0.7 \mathrm{~ms}$ was applied across the chelicerae. Expelled venom was collected from the fang tips with a tube, pooled and freeze-dried. The freeze-dried crude venom was stored at $-20^{\circ} \mathrm{C}$ prior to analysis.

\subsection{RP-HPLC Analysis}

The venom powder was dissolved with water to a final concentration of $10 \mathrm{mg} / \mathrm{mL}$, centrifuged at $14,000 \mathrm{rpm}$ for $30 \mathrm{~min}$ at $4^{\circ} \mathrm{C}$ and filtered using a $0.22 \mu \mathrm{m}$ microfilter (MILLEX GP, Millipore Ireland Ltd., Cork, Ireland). The venom solution was analyzed by RP-HPLC on a C18 column (phenomenex $100 \AA \AA, 4.6 \mathrm{~mm} \times 250 \mathrm{~mm}, 5 \mu \mathrm{m}$ ) using a Waters Alliance 2695 (Milford, MA, USA). Venom components were eluted using a linear acetonitrile gradient $(0 \%-50 \%$ acetonitrile/ $0.1 \%$ TFA in $50 \mathrm{~min})$ at a flow rate of $1.0 \mathrm{~mL} / \mathrm{min}$ [29]. Fractions $(1 \mathrm{~mL} /$ tube $)$ were collected manually by monitoring the absorbance at $215 \mathrm{~nm}$. Each fraction was lyophilized and reconstituted in $30 \mu \mathrm{L}$ of $50 \%$ acetonitrile in water/0.1\% TFA prior to MALDI-TOF-MS analysis.

\subsection{MALDI-TOF-MS Analysis}

The venom was desalted with a ZIP-TIP and analyzed using MALDI-TOF-MS (Ultraflex, Bruker Daltonics, Bremen, Germany). Ionization was achieved by irradiation with a nitrogen laser (337 nm) with a $20 \mathrm{kV}$ acceleration voltage. $10 \mathrm{mg} / \mathrm{mL} \alpha$-cyano-4 hydroxy-cinnamic acid (CCA) was 
used as the matrix. To analyze the fractions obtained by RP-HPLC, $1 \mu \mathrm{L}$ of each fraction was applied to a well overlaid with $1 \mu \mathrm{L}$ of CCA. Data were acquired using Bruker Daltonics Flexcontrol software (Bremen, Germany) and exported with Flex analysis software (Bremen, Germany). All analyses were conducted in a reflector mode.

\subsection{SDS-PAGE Analysis}

The venom powder was dissolved with water to a final concentration of $10 \mathrm{mg} / \mathrm{mL}$, centrifuged at $14,000 \mathrm{rpm}$ for $30 \mathrm{~min}$ at $4{ }^{\circ} \mathrm{C}$ and filtered using a $0.22 \mu \mathrm{m}$ microfilter (MILLEX GP, Millipore). The venom solution was analyzed by SDS-PAGE (15\% separation gel and 5\% stacking gel) using standard protocols to check the MW range and stained with Coomassie blue G-250 (Sigma-Aldrich, St. Louis, MO, USA).

\subsection{Electrophysiological Test}

Whole-cell voltage-clamp recordings of voltage-gated ion currents were made in rat DRG neurons which were acutely dissociated from 30-day old Sprague-Dawley rats and maintained in short-term primary culture according to the method described by Xiao and Liang [30]. DRG neurons with a large diameter $(>35 \mu \mathrm{m})$ and those with a relatively small diameter $(<20 \mu \mathrm{m})$ were selected for measuring TTX-S and TTX-R Na ${ }^{+}$currents, respectively. Meanwhile, TTX (final concentration: $200 \mathrm{nM}$ ) was used to separate TTX-R Na ${ }^{+}$currents from TTX-S Na ${ }^{+}$currents. Electrophysiological recordings were performed at room temperature. Suction pipettes (2.0-4.0 M 2 ) were made from borosilicate glass capillary tubes using a two-step pulling procedure on a vertical micropipette puller. For $\mathrm{Na}^{+}$ current recording, the pipette solution contained (in $\mathrm{mM}$ ) $\mathrm{CsCl} 145, \mathrm{MgCl}_{2} \cdot 6 \mathrm{H}_{2} \mathrm{O}$ 4, hydroxyethyl piperazine ethane-sulfonic acid (HEPES) 10, ethylene glycol tetraacetate (EGTA) 10, glucose 10,

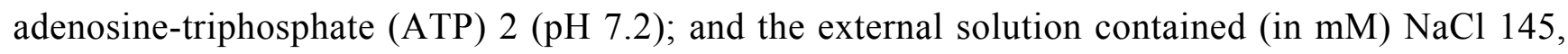
$\mathrm{KCl} 2.5, \mathrm{CaCl}_{2}$ 1.5, $\mathrm{MgCl}_{2} \cdot 6 \mathrm{H}_{2} \mathrm{O}$ 1.2, HEPES 10, and D-glucose 10 (pH 7.4). For $\mathrm{K}^{+}$current recording, the pipette solution contained (in $\mathrm{mM}$ ) $\mathrm{KCl} 135, \mathrm{KF} 25, \mathrm{NaCl} 9, \mathrm{CaCl}_{2} 0.1, \mathrm{MgCl}_{2}$ 1, EGTA 1, HEPES 10 and ATP- $\mathrm{Na}_{2}$ 3, adjusted to $\mathrm{pH} 7.4$ with $1 \mathrm{M} \mathrm{KOH}$; and the external bath solution contained (in $\mathrm{mM}$ ) $\mathrm{NaCl} 150, \mathrm{KCl} 30, \mathrm{CaCl}_{2} 5, \mathrm{MgCl}_{2}$ 4, TTX 0.3, HEPES 10 and D-glucose 10, adjusted to $\mathrm{pH} 7.4$ with $1 \mathrm{M} \mathrm{NaOH}$. For $\mathrm{Ca}^{2+}$ current recording, the internal solution contained (in $\mathrm{mM}$ ) Cs-methane sulfonate 110, phosphocreatine 14, HEPES 10, EGTA 10, ATP-Mg 5, adjusted to pH 7.3 with $\mathrm{CsOH}$; the external solution contained (in $\mathrm{mM}$ ) $\mathrm{BaCl}_{2} 10$, tetraethylammonium (TEA)-Cl 125 , TTX 0.3 and HEPES 10, adjusted to $\mathrm{pH} 7.4$ with TEA-OH. To eliminate the potential influence of differences in osmotic pressure, all internal and external solutions were adjusted to $280 \pm 5 \mathrm{mOsm}$ with sucrose. Experimental data were collected and analyzed with Pulse/Pulsefit 8.0 (HEKA Electronics, Lambrecht, Germany) and Sigmaplot 10.0 (Systat Software, San Jose, CA, USA). Macroscopic currents were filtered at $10 \mathrm{kHz}$, digitized at $3 \mathrm{kHz}$ with an EPC-10 patch-clamp amplifier (HEKA Electronics). Series resistance was kept near $5 \mathrm{M} \Omega$ and compensated $65 \%-70 \%$. Linear capacitive and leakage currents were digitally subtracted using the $\mathrm{P} / 4$ protocol. All data are presented as means \pm S.E., and $n$ is the number of independent experiments. 


\subsection{Bioactivity Assays}

The toxicity of the venom of $S$. jiafu was qualitatively assayed by intraperitoneal injection into $18-20 \mathrm{~g}$ mice of both sexes at doses of $1-10 \mathrm{mg} / \mathrm{kg}$ using $100 \mu \mathrm{L}$ solutions [in $0.9 \%$ (w/v) normal saline] and intra-abdominal injection into adult male cockroaches (Periplaneta americana) with body weights of $0.8-1.2 \mathrm{~g}$ at doses of $150-500 \mu \mathrm{g} / \mathrm{g}$ using $10 \mu \mathrm{L}$ solutions [in $0.85 \%$ (w/v) normal saline]. The $\mathrm{LD}_{50}$ was determined using five doses per animal in six animals. Mice and cockroaches were monitored for $24 \mathrm{~h}$ after injection. Data were analyzed using the modified Kaber method.

\section{Conclusions}

Spider venoms represent a valuable source of biologically active substances that selectively target a variety of vital physiological functions in both insects and mammals. The venom of $S$. jiafu is novel spider venom that has remained unexplored until now. In the present study, we performed a preliminary analysis of the biochemical and pharmacological properties of this venom. Our results indicate that the venom of $S$. jiafu contains a complex mixture of peptides, as revealed by the venom landscape analysis. The molecular masses of the venom peptides range from $1000 \mathrm{Da}$ to $10,000 \mathrm{Da}$, with most peptides in the mass range of 3000-4500 Da. The venom contains neurotoxins with activity against voltage-gated $\mathrm{Na}^{+}, \mathrm{K}^{+}$and $\mathrm{Ca}^{2+}$ channels in rat DRG neurons. Further analysis should identify antagonists of TTX-R $\mathrm{Na}_{\mathrm{v}}$ channels and T-type $\mathrm{Ca}_{\mathrm{v}}$ channels, as the venom showed inhibitory activities against both channels. The results of the present study provide a basis for further case-by-case investigations of peptide toxins from this venom.

\section{Acknowledgments}

The authors thank Xiang Xu in the College of Life Sciences of Hunan Normal University for the identification of this spider species. This work was supported by the National 973 Project of China under contract (No. 2010CB529800 and 2012CB22305), the National Natural Science Foundation of China under contract (No.31271257), the Scientific Research Fund of Hunan Provincial Education Department (13B087), the Opening Fund of Key Laboratory of Protein Chemistry and Developmental Biology of the Ministry of Education, Hunan Normal University (DF1104), and the Cooperative Innovation Center of Engineering and New Products for Developmental Biology of Hunan Province (20134486).

\section{Conflicts of Interest}

The authors declare no conflict of interest.

\section{References}

1. Coddington, J.A.; Levi, H.W. Systematics and evolution of spiders (Araneae). Annu. Rev. Ecol. Syst. 1991, 22, 565-592.

2. Saez, N.J.; Senff, S.; Jensen, J.E.; Er, S.Y.; Herzig, V.; Rash, L.D.; King, G.F. Spider-venom peptides as therapeutics. Toxins 2010, 12, 2851-2871. 
3. Platnick, N.I. The World Spider Catalog, Version 13.0; American Museum of Natural History. Available online: http://www.research.amnh.org/iz/spiders/catalog (accessed on 18 December 2012).

4. Maretic, Z. Spider Venoms and Their Effects. In Ecophysiology of Spiders; Nentwig, W., Ed.; Springer-Verlag: New York, NY, USA, 1987; pp. 142-159.

5. Zhu, M.S.; Zhang, R. Revision of the theraphosid spiders from China (Araneae: Mygalomorphae). J. Arachnol. 2008, 36, 425-447.

6. Klint, J.K.; Senff, S.; Rupasinghe, D.B.; Er, S.Y.; Herzig, V.; Nicholson, G.M.; King, G.F. Spider-venom peptides that target voltage-gated sodium channels: Pharmacological tools and potential therapeutic leads. Toxicon 2012, 60, 478-491.

7. Windley, M.J.; Herzig, V.; Dziemborowicz, S.A.; Hardy, M.C.; King, G.F.; Nicholson, G.M. Spider-venom peptides as bioinsecticides. Toxins 2012, 4, 191-227.

8. Kuhn-Nentwig, L.; Stöcklin, R.; Nentwig, W. Venom Composition and Strategies in Spiders: Is Everything Possible? In Advances in Insect Physiology; Academic Press: Burlington, MA, USA, 2011; Volume 40.

9. Escoubas, P.; Sollod, B.; King, G.F. Venom landscapes: Mining the complexity of spider venoms via a combined cDNA and mass spectrometric approach. Toxicon 2006, 47, 650-663.

10. Yuan, C.; Jin, Q.; Tang, X.; Hu, W.; Cao, R.; Yang, S.; Xiong, J.; Xie, C.; Xie, J.; Liang, S. Proteomic and peptidomic characterization of the venom from the Chinese bird spider, Ornithoctonus huwena Wang. J. Proteome Res. 2007, 6, 2792-2801.

11. Tang, X.; Zhang, Y.; Hu, W.; Xu, D.; Yang, X.; Li, Y.; Jiang, L.; Liang, S. Molecular diversification of peptide toxins from the tarantula Haplopelma hainanum (Ornithoctonus hainana) venom based on transcriptomic, peptidomic, and genomic analyses. J. Proteome Res. 2010, 9, 2550-2564.

12. Liao, Z.; Cao, J.; Li, S.; Yan, X.; Hu, W.; He, Q.; Chen, J.; Tang, J.; Xie, J.; Liang, S. Proteomic and peptidomic analysis of the venom from Chinese tarantula Chilobrachys jingzhao. Proteomics 2007, 7, 1892-1907.

13. Mantegazza, M.; Curia, G.; Biagini, G.; Ragsdale, D.S.; Avoli, M. Voltage-gated sodium channels as therapeutic targets in epilepsy and other neurological disorders. Lancet Neurol. 2010, 9, 413-424.

14. Ogata, N.; Tatebayashi, H. Kinetic analysis of two types of $\mathrm{Na}^{+}$channels in rat dorsal root ganglia. J. Physiol. 1993, 466, 9-37.

15. Ho, C.; O’Leary, M.E. Single-cell analysis of sodium channel expression in dorsal root ganglion neurons. Mol. Cell. Neurosci. 2011, 46, 159-166.

16. Harriott, A.M.; Gold, M.S. Contribution of primary afferent channels to neuropathic pain. Curr. Pain Headache Rep. 2009, 13, 197-207.

17. Qiao, G.F.; Li, B.Y.; Zhou, Y.H.; Lu, Y.J.; Schild, J.H. Characterization of persistent TTX-R $\mathrm{Na}^{+}$currents in physiological concentration of sodium in rat visceral afferents. Int. J. Biol. Sci. 2009, 5, 293-297.

18. Rasband, M.N.; Park, E.W.; Vanderah, T.W.; Lai, J.; Porreca, F.; Trimmer, J.S. Distinct potassium channels on pain-sensing neurons. Proc. Natl. Acad. Sci. USA 2001, 98, 13373-13378.

19. Takeda, M.; Tsuboi, Y.; Kitagawa, J.; Nakagawa, K.; Iwata, K.; Matsumoto, S. Potassium channels as a potential therapeutic target for trigeminal neuropathic and inflammatory pain. Mol. Pain 2011, 7, doi:10.1186/1744-8069-7-5.

20. Roeper, J.; Pongs, O. Presynaptic potassium channels. Curr. Opin. Neurobiol. 1996, 6, 338-341. 
21. Catterall, W.A. Voltage-gated calcium channels. Cold Spring Harb. Perspect. Biol. 2011, 3, doi:10.1101/cshperspect.a003947.

22. Hofmann, F.; Biel, M.; Flockerzi, V. Molecular basis for $\mathrm{Ca}^{2+}$ channel diversity. Annu. Rev. Neurosci. 1994, 17, 399-418.

23. Olivera, B.M.; Miljanich, G.P.; Ramachandran, J.; Adams, M.E. Calcium channel diversity and neurotransmitter release: The omega-conotoxins and omega-agatoxins. Annu. Rev. Biochem. 1994, 63, 823-867.

24. Nelson, M.T.; Todorovic, S.M.; Perez-Reyes, E. The role of T-type calcium channels in epilepsy and pain. Curr. Pharm. Des. 2006, 12, 2189-2197.

25. Yaksh, T.L. Calcium channels as therapeutic targets in neuropathic pain. J. Pain 2006, 7, 13-30.

26. Cao, Y.Q. Voltage-gated calcium channels and pain. Pain 2006, 126, 5-9.

27. Liang, S.P.; Qin, Y.B.; Zhang, D.Y.; Pan, X.; Chen, X.D.; Xie, J.Y. Biological characterization of spider (Selenocosmia huwena) crude venom. Zool. Res. 1993, 14, 60-65.

28. Liang, S.P. An overview of peptide toxins from the venom of the Chinese bird spider Selenocosmia huwena Wang [=Ornithoctonus huwena (Wang)]. Toxicon 2004, 43, 575-585.

29. Liu, Z.H.; Dai, J.; Dai, L.J.; Deng, M.C.; Hu, Z.; Hu, W.J.; Liang, S.P. Function and solution structure of Huwentoxin-X, a specific blocker of N-type calcium channels, from the Chinese bird spider Ornithoctonus huwena. J. Biol. Chem. 2006, 281, 8628-8635.

30. Xiao, Y.C.; Liang, S.P. Inhibition of sodium channels in rat dorsal root ganglion neurons by hainantoxin-IV, a novel spider toxin. Acta Biochim. Biophys. Sin. 2003, 35, 82-85.

(C) 2014 by the authors; licensee MDPI, Basel, Switzerland. This article is an open access article distributed under the terms and conditions of the Creative Commons Attribution license (http://creativecommons.org/licenses/by/3.0/). 